\title{
SISTEM PEMBELAJARAN ONLINE BERBASIS APLIKASI WEB MENGGUNAKAN FRAMEWORK CODEIGNITER
}

\author{
Purnomo Hadi Susilo', M. Ghofar Rohman ${ }^{2}$ \\ ${ }^{1,2)}$ Teknik Informatika, Universitas Islam Lamongan \\ J1. Veteran No.53A Lamongan \\ Email : hadyjelak.purnomo@gmail.com ${ }^{1}$, m.ghofarrohman@unisla.ac.id ${ }^{2}$
}

\begin{abstract}
ABSTRAK
Perkembangan teknologi informasi telah menghasilkan begitu banyak layanan bagi masyarakat yang telah menerapkan Information and Communication Technology (ICT) bahkan dalam dunia pendidikan pelayanannya hapir sudah berbasis ICT. Salah satu bentuk penerapan ICT pada pendidikan yaitu sistem pembelajaran online (SPON). SPON merupakan sebagian sistem pendidikan yang memanfaatkan aplikasi elektronik sebagai pendukung proses belajar mengajar dengan media internet atau jaringan komputer. Tujuan penerapan SPON yaitu untuk menghadapi beberapa kendalan saat sistem pembelajaran masih menggunkan metode lama (tradisional). Metode tradisional yang diterapkan di era milenial dianggap sudah tidak relevan sehingga terdapat beberapa kendala dalam pelaksanaan, seperti keterbatasan tempat, lokasi, waktu dan budaya pendidikan yang berkembang sesuai pada jamanya, yang segala sesuatunya dapat diperoleh hanya dengan melalui smartphone. Tujuan penelitian ini menghasilkan sistem pembelajaran baru yang dapat diakses dan dapat dilakukan dimanapun tanpa dibatasi oleh tempat, waktu, maupun lokasi. Penelitian ini menggunakan model penelitian R\&D agar hasil penelitian dapat dijadikan sebagai perkembangan suatu gaya proses sistem pembelajaran baru yang dapat menyesuaikan budaya belajar peserta didik di era milenial yang dapat dilakukan tanpa dibatasi oleh tempat, waktu dan keadaan tertentu.
\end{abstract}

Kata kunci: Media, Pembelajaran, Online, Milenial, Digita

\begin{abstract}
The development of information technology has produced so many services for people who have implemented Information and Communication Technology (ICT) even in the world of education, the services are almost already ICT-based. One form of applying ICT to education is the online learning system (SPON). SPON is part of an education system that utilizes electronic applications to support teaching and learning process with internet media or computer networks. The purpose of implementing SPON is to face some obstacles when the learning system is still using the old (traditional) method. Traditional methods applied in the millennial era are considered to be irrelevant so there are several obstacles in implementation, such as limited space, location, time and culture of education that develops according to time, all of which can be obtained only through a smartphone. The purpose of this study is to produce a new learning system that can be accessed and can be done anywhere without being limited by place, time, or location. This study uses an $R \& D$ research model so that research results can be used as a development of a new learning system process style that can adjust the learning culture of students in the millennial era that can be carried out without being limited by specific places, times and circumstances.
\end{abstract}

Keywords: Media, Learning, Online, Millennial, Digital

\section{PENDAHULUAN}

\subsection{Latar Belakang}

Peningkatan teknologi informasi telah ber-

kembang dengan sangat cepat dan mampu memberikan dampak positif pada masyarakat. Perkembangan tersebut telah menghasilkan begitu banyak layanan bagi masyarakat dalam pelayananya bahkan dalam dunia pendidikan. Depdiknas bahkan sudah menyambut dengan baik perkembangan tersebut yaitu melalui penerapan dalam berbagai pengelolahan atau administrasi pendidikan berbasis teknologi informasi dan komputer (TIK). Hal ini menunjukkan bahwa dalam dunia pendidikan akan dapat ikut berkembang secara linier ketika proses pembelajaran sudah mengaplikasikan perkembangan teknologi informasi. Tujuan kebijakan tersebut yaitu melatih mahasiswa agar mempunyai kompetensi dalam memahami, mengetahui dan dapat berinteraksi secara langsung dengan teknologi terkini sesuai perkembangannya.

Keterkaitan dalam pemanfaatan teknologi dengan proses pembelajaran berbasis TIK sebagai media alternatif dalam pembelajaran, Universitas 
Islam Lamongan (UNISLA) perlu melakukan langkah strategis dan tepat guna. Langkah-langkah strategis awal yang dapat dilakukan yaitu analisis kebutuhan dan mempesiapkan semua kebutuhan yang dibutuhkan dalam penerapan pembelajaran modern yakni sistem pembelajaran online (SPON). Pembelajaran online merupakan sistem pembelajaran yang mengaplikasikan komponen elektronik sebagai sarana pendukung proses pembelajaran dengan jaringan internet atau jaringan komputer. Hal ini dapat disimpulkan bahwa para dosen dan mahasiswa perlu melakukan prosedur yang strategis dan sistematis agar dapat mengetahui cara menerapkan sistem pembelajaran online dalam proses belajar mengajar.

Pertukaran budaya pembelajaran yang didukung dengan perkembangan teknologi telah menunjukkan hasil yang signifikan pada proses pertukaran pengetahuan atau pembelajaran pada proses pembelajaran. Pembelajaran yang diterapkan cenderung berbasis pada isi pembelajaran dan bersifat satu arah serta abstrak dan hanya dapat diketahui oleh golongan tertentu saja, sehingga cenderung pasif. Perkembangan TIK pada bidang pendidikan telah merubah dari proses belajar, berbasis masalah, bersifat kontekstual dan sudah tidak dibatasi pada golongan tertentu saja, akan tetapi semua yang membutuhkan dapat masuk dalam proses pembelajaran tesebut. Pada penerapan proses pembelajaran seperti ini peserta didik dilatih supaya dapat belajar secara mandiri dan lebih aktif dengan mengoptimalkan referensi pembelajaran yang telah ada.

\subsection{Rumusan Masalah}

a. Bagaimana mengembangkan SPON sebagai inovasi sistem pembelajaran di era milenial?

b. Bagaimana tingkat efektivitas SPON pada sistem pembelajaran di era milenial?

\subsection{Tujuan Penelitian}

a. Mengembangkan sistem pembelajaran baru yaitu dengan melakukan pembelajaran secara online.

b. Mengetahui tingkat efektivitas sistem pembelajaran online yang telah dikembangkan.

\subsection{Referensi}

\section{a) Pengembangan Media Pembelajaran}

Media Pembelajaran merupakan komponen yang cukup penting dalam pelaksanaan sistem pembelajaran. Hal ini dikarenakan tanpa adanya sebuah media, maka upaya komunikasi tidak akan tercipta dan proses pembelajaran tidak dapat berjalan secara optimal karena media pembelajaran merupakan bagian komponen yang tidak terpisahkan dalam sistem pembelajaran. Wardaya dan Sumartini (2016:35) menjelaskan, media pembelajaran adalah perantara atau alat pengantar pesan yang diberikan oleh pengirim kepada penerima pesan agar individu tersebut melakukan sebuah kegiatan pembelajaran dan materi pembelajaran yang disampaikan dapat diterima dengan baik oleh pesertadidik. Hal ini menunjukan bahwa media pembelajaran merupakan wadah sebuah pesan yang oleh pengirim atau penyalurnya ingin disampaikan kepada penerima tersebut, yaitu peserta didik.

Munadi (2010:8) menjelaskan bahwa media pembelajaran merupakan segala sesuatu yang dapat digunakan sebagai sarana untuk menyampaikan dan menyalurkan pesan secara terencana dengan tujuan terciptanya suasana pembelajaran yang kondusif dimana penerimaannya dapat melakukan proses pembelajaran secara efektif dan efisien. Karwati dan Priansa (2014: 223) memperkuat pernyataan tersebut menjelaskan bahwa media pembelajaran merupakan sebuah perantara yang dapat digunakan sebagai penyalur pesan kepada pihak lain. Dari beberapa penjelasan tersebut dapat disimpulkan bahwa yang dimaksud dengan media pembelajaran yaitu alat atau segala sesuatu yang dapat digunakan sebagai sarana menyalurkan atau menyampaikan sebuah pesan kepada seseorang yang dituju, yaitu peserta didik.

Hal penting yang harus dilakukan oleh seorang pengajar atau pendidik dalam perencanaan pengembangan media pembelajaran (Wardaya dan Sumartini, 2016:57), apapun jenis kegiatannya harus melakukan prosedur sistematik pada saat pengembangannya. Langkah-langkah tersebut yaitu: 1) analisis kebutuhan dan karakteristik peserta didik, 2) merencanakan tujuan pembelajaran, 3) merumuskan materi secara sistematis, 4) membuat instrumen evaluasi, 5) mendesain media, dan 6) merevisi jika dibutuhkan. Penjelasan di atas menunjukkan bahwa sebelum melakukan kegiatan pembelajaran, maka seorang pengajar atau pendidik harus mendesain dan merencanakan media pembelajaran tersebut terlebih dahulu. Perencanaan dilakukan mulai dari mengidentifikasi kebutuhan, selanjutnya kebutuhan tersebut dapat dirumuskan melalui kegiatan observasi khususnya dalam proses pembelajaran beserta penggunaannya agar dapat meningkatkan hasil pembelajaran peserta didik.

\section{b) Pengembangan SPON}

Penunjang keberhasilan pengembangan SPON diantaranya yaitu adanya pemahaman secara seksama tentang bagaimana teknologi pembelajaran dapat meningkatkan ativitas belajar dan bagaimana sistem yang dikembangkan dapat dipadukan secara efektif serta dapat berjalan beriringan dengan sistem pembelajaran yang telah diterapkan. Tujuan dari hal ini yaitu untuk menjamin bahwa apapun pendekatan atau metode 
dan hasil pembelajaran yang direncanakan, potensi belajar peserta didik tetap dapat dimaksimalkan. Agar supaya proses dalam pembelajaran dapat terjadi, baik pada konteks sosial dan kurikuler serta fisik. Hubungan individual pada suatu kelompok yang melingkupi aktivitas pembelajaran juga dapat mempengaruhi hasil belajar mrngajar. Konteks kurikuler juga dapat mempengaruhi proses pembelajaran, yakni melalui pendekatan pedagogis tertentu yang disarankan pada saatnya harus sesuai dengan kondisi peserta didik, sumber daya yang telah tersedia pada lingkungan belajar dan hasil yang direncanakan sebelumnya.

Tiga elemen tersebut harus diperhatikan dalam perencanaan aktivitas pembelajaran pada konteks teknologi dengan mempertimbangkan isuisu yang terkait. Berikut adalah beberapa isu terkait yang harus dipertimbankan dalam mengembangkan SPON (JISC, 2004:16-17).

1. Peserta didik, yaitu kebutuhan, motivasi belajar, pengalaman belajar, keterampilan sosial dan interpersonal, metode belajar yang disukai, serta kemampuan TIK.

2. Hasil belajar yang diinginkan, bertambahnya pengetahuan, keterampilan akademik dan sosial, meningkatnya motivasi dan kemampuan dalam berkembang.

3. Lingkungan belajar, yaitu kontak fisik/tatap muka, online/virtual, referensi, peralatan, fasilitas dan layanana belajar serta relevansinya dengan kebutuhan peserta didik.

4. Aktivitas belajar yang dapat mengarahkan secara langsung kepada peserta didik terhadap hasil belajar yang telah direncanakan.

5. Pendekatan yang diambil harus relevan dengan kebutuhan dan gaya belajar peserta didik, keadaan lingkungan pembelajaran, dan hasil belajar yang diharapkan. Hal ini dapat dilakukan dengan menggunakan media digital baik itu yang berupa gambar, video, atau audio yang telah dilengkapi dengan fasilitas berkomunikasi atara peserta didik dengan guru/dosen agar keduanya dapat saling berinteraksi dan menciptakan suasana pembelajaran online mirip dengan suasana tatap muka.

\section{c) Pengujian SPON}

Agar sistem yang dikembangkan dapat berjalan sesuai dengan yang direncanakan, maka ada beberapa aspek yang perlu diperhatikan yaitu 1) aspek rekayasa perangkat lunak, 2) aspek desain pembelajaran, dan 3) aspek komunikasi visual. Cara mensajikan indikator penilaian termasuk mekanisme evaluasi, tidak dengan digabungkan menjadi satu akan tetapi dipisah dan masingmasing aspek dinilai secara mandiri oleh responden yang kompeten (para ahli) sesuai dengan tiga aspek tersebut (Wahono, 2006).
Ketika aspek-aspek tersebut telah selesai diujicobakan dan mendapatkan hasil yang sesuai dengan perencanaan, maka selanjutnya dapat dilakukan ujicoba kepada pengguna dengan metode usability testing.

Pengujian usability testing atau uji ketergunaan merupakan suatu metode untuk meningkatkan kemudahan pada pemakaian selama proses desain (Rahadi, 2014:664). Usability testing mengacu pada bagaimana pengguna bisa dengan mudah mempelajari dan menggunakan produk yang dikembangkan untuk memperoleh tujuannya dan seberapa puaskah terhadap penggunannya. Agar pengujian ini dapat tercapai secara maksimal, maka terdapat beberapa aspek penilaian yang harus diperhatikan, yaitu 1) usefullness (Kegunaan); 2) efficiency (Efisiensi); 3) Efectiveness (Efektivitas); dan 4) Satisfaction (Kepuasan) (Susilo, 2016: 975). Rubin \& Chisnell (2008:4), memperkuat pernyataan tersebut menjelaskan bahwa metode Usability Testing dapat dilakukan dengan memperhatikan 5 komponen berikut, yaitu Usefulness (Kegunaan), Efficiency (Efisiensi), Effectiveness (Keefektifan)/Errors frequency, Learnability (Kemampuan dipelajari)/Memorability, dan Satisfaction (Kepuasan).

\section{PEMBAHASAN}

\subsection{Metode Penelitian}

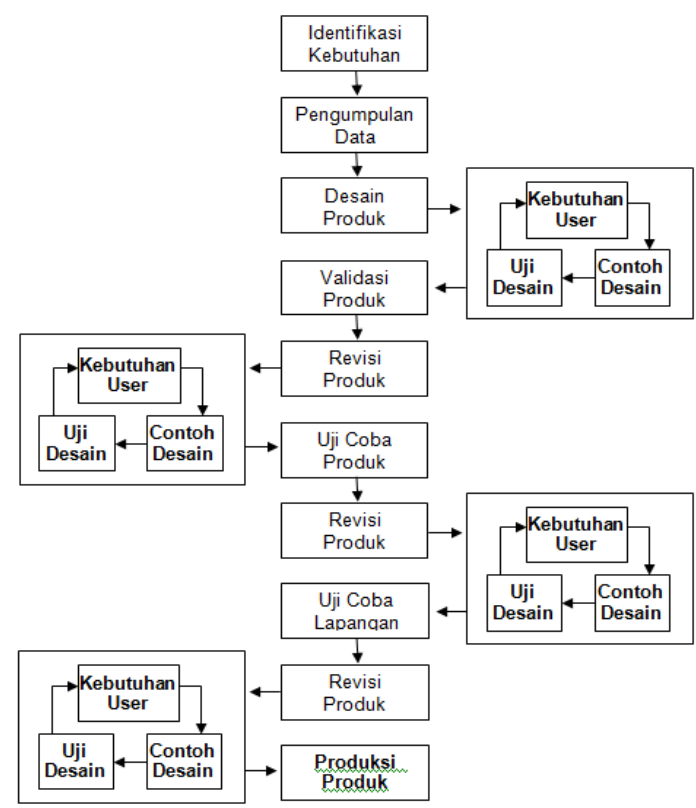

Gambar 1. Langkah-Langkah Penelitian

Penelitian ini merupakan jenis penelitian dan Pengembangan (R\&D) hasil modifikasi Model pengembangan (Sugiono, 2010: 409, dan Kadir, 2003: 566) yang secara rinci dapat dilihat pada Gambar 1. 


\subsection{Instrumen Pengujian}

Pada penelitian ini intrumen pengujian yang digunakan yaitu dalam bentuk kuesioner yang berisi serangkaian pernyataan. Pernyataan yang disajikan pada instrumen tersebut merupakan bentuk penjabaran dari indikator metode usability testing. Adapun pernyataan-pernyataan pada lembar kuesioner tersebut dapat dilihat pada Tabel 1.

Tabel 1. Daftar Pernyataan Uji Usability

\begin{tabular}{|c|c|}
\hline Indikator & Pernyataan/Pertanyaan \\
\hline Usefullness & $\begin{array}{l}\text { 1. Sistem bermanfaat untuk meningkat- } \\
\text { kan proses pembelajaran. } \\
\text { 2. Sistem dapat memberikan kontrol } \\
\text { yang lebih baik terhadap proses } \\
\text { pembelajaran. } \\
\text { 3. Sistem dapat menyampaikan infor- } \\
\text { masi/materi pembelajaran dalam } \\
\text { waktu yang singkat. } \\
\text { 4. Sistem dapat memenuhi kebutuhan } \\
\text { dalam proses pembelajaran. }\end{array}$ \\
\hline Efficiency & $\begin{array}{l}\text { 5. Sistem hanya memerlukan langkah- } \\
\text { langkah yang sedikit saat digunakan. } \\
\text { 6. Sistem dapat dipahami dan } \\
\text { digunakan dengan mudah walaupun } \\
\text { tanpa panduan. } \\
\text { 7. Sistem dapat digunakan dengan } \\
\text { mudah baik sesekali (jarang) } \\
\text { ataupun secara rutin. } \\
\text { 8. Sistem dapat memberikan informasi } \\
\text { perbaikan kesalahan dengan cepat } \\
\text { dan mudah. }\end{array}$ \\
\hline Effectiveness & $\begin{array}{l}\text { 9. Peserta didik dapat dengan cepat } \\
\text { mempelajari cara menggunakan } \\
\text { sistem. } \\
\text { 10. Peserta didik dapat dengan mudah } \\
\text { mengingat langkah-langkah cara } \\
\text { menggunakan sistem. } \\
\text { 11. Peserta didik dapat dengan mudah } \\
\text { mempelajari cara menggunakan } \\
\text { sistem. } \\
\text { 12. Peserta didik dapat dengan cepat } \\
\text { menjadi terampil saat menggunakan } \\
\text { sistem }\end{array}$ \\
\hline Satisfaction & $\begin{array}{l}\text { 13. Sistem dapat menciptakan rasa } \\
\text { menyenangkan saat digunakan. } \\
\text { 14. Sistem dapat berfungsi sesuai } \\
\text { dengan harapan. } \\
\text { 15. Sistem dapat menciptakan rasa } \\
\text { nyaman saat digunakan. }\end{array}$ \\
\hline
\end{tabular}

\subsection{Analisis Data}

Penelitian dilakukan kepada seluruh mahasiswa semester V (lima) sejumlah 150 mahasiswa dengan berkolaborasi antara dosen dan observer. Hasil penelitian kemudian dapat diketahui dari data yang telah diambil menggunakan instrumen kuesioner yang dibagikan kepada seluruh subjek coba. Data yang telah dikumpulkan dari kuesioner kemudian dihitung dan dianalisis menggunakan rumus yang diambil dari Akbar (2013), yaitu sebagai berikut:

Keterangan:

$$
\mathrm{P}=\frac{\sum \mathrm{x}}{\sum \mathrm{xi}} \times 100 \%
$$

$$
\begin{array}{ll}
\mathrm{P} & \begin{array}{l}
\text { : Skor persentase } \\
: \text { Jumlah keseluruhan } \\
\text { responden }
\end{array} \\
\sum \mathrm{x} & \begin{array}{l}
: \text { Jumlah keseluruhan nilai } \\
\text { ideal suatu item }
\end{array} \\
100 \% & \begin{array}{l}
: \text { Bilangan konstanta } \\
\text { B }
\end{array}
\end{array}
$$

Dalam menentukan kriteria pencapaian hasil yang didapat dilihat pada Tabel 2 .

Tabel 2. Kriteria Pencapaian

\begin{tabular}{|c|l|}
\hline Pencapaian (\%) & Tingkat Capaian \\
\hline $81 \%-100 \%$ & Sangat Tinggi \\
\hline $61 \%-80 \%$ & Tinggi \\
\hline $41 \%-60 \%$ & Cukup \\
\hline $21 \%-40 \%$ & Rendah \\
\hline $0 \%-20 \%$ & Sangat Rendah \\
\hline
\end{tabular}

(Sumber: Akbar, 2013)

\subsection{Konteks Diagram}

Perancangan konteks diagram pada Gambar 2 menunjukkan bahwa pada sistem SPON terdapat tiga peran pengguna yang dapat menjalankan dengan tingkatan level akses user. Tiga akses user tersebut yaitu Admin (dapat melakukan seluruh manajemen sistem), pengajar (dapat mengakses manajemen data yang terkait saja), dan peserta didik (hanya dapat memanipulasi data pribadi). Secara terstruktur dan rinci dapat dilihat secara detail pada Gambar 2.

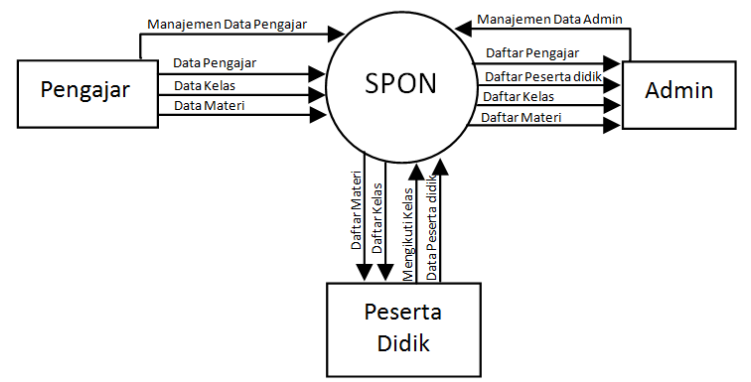

Gambar 2. Konteks Diagaram SPON

\subsection{Rancangan Basisdata}

Perancangan basisdata dalam pengembangan sistem merupakan hal terpenting, karena berfungsi untuk menyimpan seluruh data atau kegiatan yang dilakukan pada sistem. Sistem basisdata pada sistem yang dibangun dapat dilihat pada Gambar 3. 


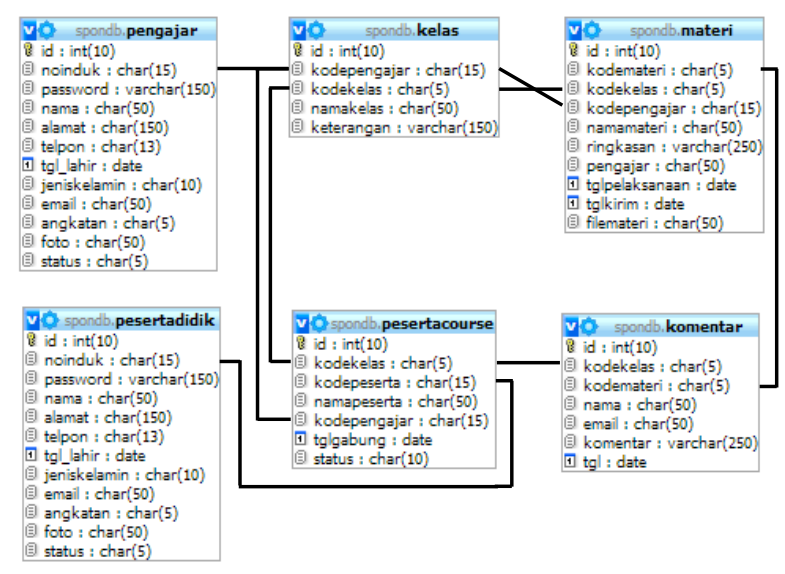

Gambar 3. Rancangan Basisdata

Peran basisdata digunakan untuk menyimpan seluruh data dalam sebuah tabel yang saling berkorelasi satu sama lain, yaitu: tabel (1) pengajar; (2) pesertadidik; (3) kelas; (4) pesertacourse; (5) materi; dan (6) komentar. Seluruh data yang rekam pada sistem saat dijalankan, maka secara otomatis data-data tersebut akan disimpan pada basisdata sesuai dengan tabel masing-masing.

\subsection{Implementasi Sistem}

Pada saat pengguna menjalankan aplikasi, sebelum masuk pada inti aplikasi yang dibangun, tampilan awal yang harus dilakukan yaitu Login terlebih dahulu. Form ini bertujuan agar sistem dapat mengetahui level pangguna yang akan masuk (admin, pengajar, atau peserta didik) dan hanya penguna terdaftar saja yang dapat mengakses lebih lanjut. Tampilah halaman Login secara detai dapat dilihat pada Gambar 4.

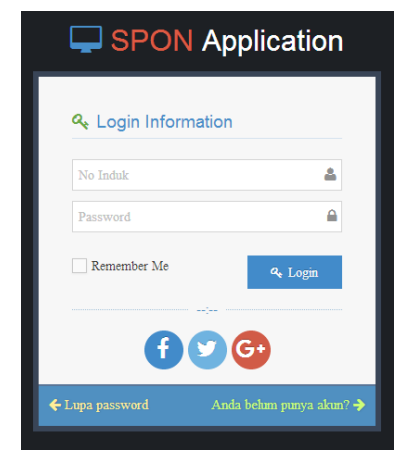

Gambar 4. Halaman Login

Pada form login tersebut pengguna yang belum mempunyai akun dapat melakukan pendaftaran dengan menekan penyataan "Anda belum punya akun?". Akan tetapi apabila sudah mempunyai akun dan lupa kata sandinya, maka dapat reques kata sandi dengan menekan pernyataan "Lupa password?". Seluruh form ini dapat digunakan oleh seluruh pengguna yang ingin menggunkan sistem tersebut.

Penggunaka yang berhasil masuk kesistem akan diarahkan pada halaman utama sesuai dengan levelnya saat melakukan login. Sebagai contoh halaman awal admin (Gambar 5) dapat diketahui terdapat beberapa menu/fitur yang dapat diakses, yaitu manajemen pengajar, manajemen peserta didik, manajemen kelas, manajemen materi, dan seluruh data yang ada pada sistem. Adapaun secara terperinci dapat dilihat pada Gambar 5.

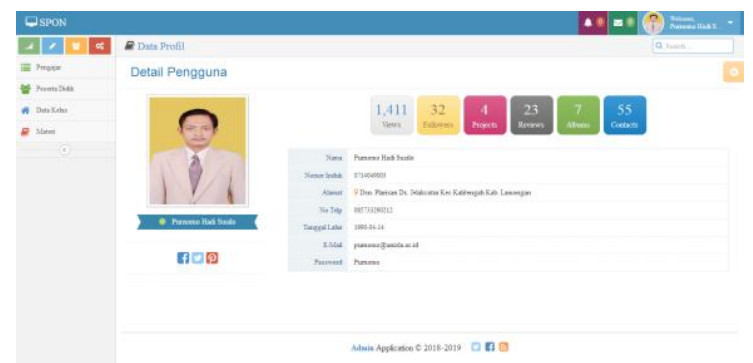

Gambar 5. Manajemen Data Admin

Pada pengguna yang berhasil masuk dengan level Pengajar, fitur/menut yang disediakan juga akan berbeda. Karena pengajar hanya dibatasi dapat melakukan manajemen sistem seputar data terkait dengan akun serta data peserta didik yang mengikuti kelasnya. Fitur/menu yang disediakan pada level Pengajar diantaranya yaitu manajemen data kelas dan manajemen data materi pelajaran. Adapun tampilan secara detai dapat dilihat pada Gambar 6.

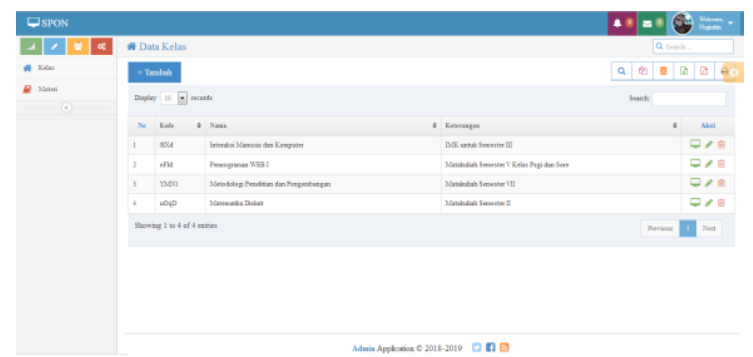

\section{Gambar 6. Manajemen Data Guru}

Pada setiap halaman manajemen pengguna dapat melihat data, menambah, mengubah, dan menghapus data-data yang dikehendaki. Manajemen data yang dimaksud dapat dilakukan pada kolom Aksi pada tampilan sitem tersebut.

\subsection{Hasil Ujicoba Sistem}

Hasil penelitian menunjukkan bahwa pernyataan responden terhadap efektifitas SPON sebagai media pembelajaran tergolong efektif. Hal ini dibuktikan dengan hasil penyebaran kuesioner yang skor persentasenya sebesar 77,33\% (Lihat Tabel 2). Walaupun demikian masih terdapat beberapa hal yang masih harus diperhatikan agar sistem dapat diimplementasikan secara maksimal. 
Hal-hal yang perlu diperhatikan tersebut diantaranya yaitu: (1) pengguna harus benar-benar dapat menjalankan sistem tersebut; (2) adanya dukungan dari semua aspek yang terkait dengan sistem; (3) pengguna harus dapat berinteraksi, mendapat pengalaman pembelajaran, serta materi yang sesuai dengan kebutuhan; dan 4) dapat diakses oleh semua hardware atau tempat dengan fasilitas yang mendukung.

Tabel 2. Hasil Ujicoba Sistem SPON

\begin{tabular}{lccccr}
\hline & I-1 & I-2 & I-3 & I-4 & TOTAL \\
\hline V-A & 70,52 & 78,14 & 76,43 & 71,61 & 74,18 \\
V-B & 72,15 & 79,52 & 80,17 & 80,57 & 78,10 \\
V-C & 80,45 & 82,28 & 82,01 & 80,57 & 81,33 \\
V-D & 73,45 & 71,56 & 80,37 & 77,48 & 75,72 \\
TOTAL & 74,14 & 77,88 & 79,75 & 77,56 & $\mathbf{7 7 , 3 3}$ \\
\hline
\end{tabular}

Keterangan:

$\begin{array}{ll}\mathrm{I}-1 & \text { : Usefulness / Kegunaan } \\ \mathrm{I}-2 & \text { : Efficiency / Efisiensi } \\ \mathrm{I}-3 & \text { : Effectiveness / Efektifitas } \\ \mathrm{I}-4 & \text { : Satisfaction / Kepuasan }\end{array}$

\section{KESIMPULAN}

Hasil ujicoba sistem menunjukkan bahwa aplikasi yang dibangun (SPON) dapat digunakan dan menunjukkan hasil yang efektif saat diimplementasikan sebagai sistem pembelajaran di era milenial. SPON akan dapat berjalan dengan baik dan efektif ketika seluruh stakeholder yang terkait bisa saling mendukung. Agar materi yang disampaikan dengan menggunakan SPON dapat sesuai dengan kebutuhan peserta didik, maka pengajar harus melakukan analisis kebutuhan terlebih dahulu. Tujuan diadakanya analisis kebutuhan yaitu agar pengajar dapat menentukan konten materi yang akan dimasukkan dalam sistem SPON tersebut sesuai dengan kebutuhan peserta didik. Peserta didik akan tertarik dan merespon positif saat materi dan isi yang disajikan oleh pengajar menarik dan benar-benar dibutuhkan.

\section{PUSTAKA}

Akbar, Sa'dun. 2013. Instrumen Perangkat Pembelajaran. Bandung: Remaja Rosdakarya. Akbar, Sa'dun \& Sriwiyana, Hadi. 2010. Pengembangan Kurikulum dan Pembelajaran: Ilmu Pengetahuan Sosial (IPS). Yogyakarta: Cipta Media.

Kadir, Abdul. 2003. Pengenalan Teknologi Informasi. Yogyakarta: ANDI.

Karwati, E dan Priansa, D. 2014. Manajemen kelas. Bandung: Alfabeta.
Munadi, Y. 2010. Media pembelajaran; sebuah pendekatan baru. Jakarta: Referensi (Gaung Persada Press Group).

Munir. 2009. Pembelajaran jarak jauh berbasis teknologi informasi dan komunikasi. Bandung: Alfabeta.

Rahadi, Dedi Rianto. 2014. Pengukuran Usability Sistem Menggunakan Use Questionnaire Pada Aplikasi Android. Jurnal Sistem Informasi (JSI), 6(1):661-671.

Rubin, Jeffrey \& Chrisnell, Dana. 2008. Handbook of Usability Testing: How to Plan, Design and Conduct Effective Tests. Indiana: Wiley Publishing.

Rusman, dkk. 2011. Pembelajaran berbasis teknologi informasi dan komunikasi, mengembangkan profesionalitas guru. Jakarta: PT. Raja Grafindo.

Sugiyono. 2010. Metode Penelitian Pendidikan Pendekatan Kuantitatif, Kualitatif, dan R\&D. Bandung: Alfabeta.

Susilo, Purnomo Hadi. 2016. Sistem Manajemen Mutu ISO 9001:2008 Digital Berbasis Web Di SMK Widyagama Malang. Jurnal Pendidikan: Teori, Penelitian, dan Pengembangan, E-ISSN: 2502-471X 5(1): 975.

Wahono, Romi Satria. 2006. Aspek dan Kriteria Penilaian Media Pembelajaran. Diakses dari http://romisatriawahono.net/2006/06/21/aspe k-dan-kriteria-penilaian-media-pembelajaran/ Tanggal 12 September 2018.

Wardaya, Cep Unang \& Sumartini, Tini. 2016. Media dan sumber belajar di TK. Bandung: PPPPK TK dan PLB. 